AperTO - Archivio Istituzionale Open Access dell'Università di Torino

\title{
Assessment of the ternary Fe-Si-B phase diagram
}

\section{This is the author's manuscript}

Original Citation:

Availability:

This version is available http://hdl.handle.net/2318/145357

since $2015-12-30 T 15: 45: 55 Z$

Published version:

DOI:10.1016/j.calphad.2013.08.001

Terms of use:

Open Access

Anyone can freely access the full text of works made available as "Open Access". Works made available under a Creative Commons license can be used according to the terms and conditions of said license. Use of all other works requires consent of the right holder (author or publisher) if not exempted from copyright protection by the applicable law. 


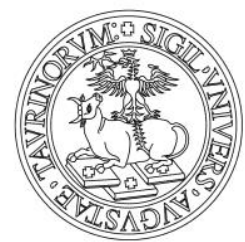

\section{UNIVERSITÀ DEGLI STUDI DI TORINO}

This Accepted Author Manuscript (AAM) is copyrighted and published by Elsevier. It is posted here by agreement between Elsevier and the University of Turin. Changes resulting from the publishing process - such as editing, corrections, structural formatting, and other quality control mechanisms - may not be reflected in this version of the text. The definitive version of the text was subsequently published in CALPHAD: Computer Coupling of Phase Diagrams and Thermochemistry 43 (2013) 40-47, 31 December 2013, digital object identifier link: http://dx.doi.org/10.1016/j.calphad.2013.08.001

Assessment of the ternary $\mathrm{Fe}-\mathrm{Si}-\mathrm{B}$ phase diagram

Marco G. Poletti, Livio Battezzati

You may download, copy and otherwise use the AAM for non-commercial purposes provided that your license is limited by the following restrictions:

(1) You may use this AAM for non-commercial purposes only under the terms of the CC-BYNC-ND license.

(2) The integrity of the work and identification of the author, copyright owner, and publisher must be preserved in any copy.

(3) You must attribute this AAM in the following format: Creative Commons BY-NC-ND license (http://creativecommons.org/licenses/by-nc-nd/4.0/deed.en), [+ Digital Object Identifier link http://dx.doi.org/10.1016/i.calphad.2013.08.001 to the published journal article on Elsevier's ScienceDirect ${ }^{\circledR}$ platform] 


\title{
Assessment of the ternary Fe-Si-B phase diagram
}

\author{
Marco G. Poletti, Livio Battezzati
}

Dipartimento di Chimica, Università di Torino, Via P. Giuria 7, 10125 Torino, Italy

\begin{abstract}
An improvement of the thermodynamic description of the ternary Fe-Si-B system by means of Calphad method has been carried out in this work considering not only the equilibria involving the stable $\mathrm{Fe}_{2} \mathrm{~B}$ phase but also the metastable ternary equilibria in which the $\mathrm{Fe}_{3} \mathrm{~B}$ phase occurs. Furthermore, the glass transition is introduced in the Calphad framework as a second-order one using the tools provided by the Hillert-Jarl formalism of the ferromagnetic transitions not yet applied to $\mathrm{Fe}-\mathrm{B}$ and $\mathrm{Fe}-\mathrm{Si}$ - $\mathrm{B}$. The assessments have been made using data available in the literature regarding both the amorphous and crystalline phases. The results improve the previous ones for the glassy phase while keeping the agreement with experimental data concerning stable equilibria.
\end{abstract}

Keywords: Iron-Silicon-Boron phase diagram; Amorphous metals; Metastable eutectic; Glass transition.

\section{Introduction}

The most recent thermodynamic assessments of the $\mathrm{Fe}-\mathrm{B}$ and $\mathrm{Fe}-\mathrm{Si}-\mathrm{B}$ glass forming systems were performed, respectively, by Palumbo and Tokunaga [1,2].

Fe-Si-B amorphous alloys are attractive technological materials both for their good magnetic properties and outstanding mechanical behaviour [3]. $\mathrm{Fe}_{78} \mathrm{Si}_{13} \mathrm{~B}_{9}$ is one of the commercially available amorphous alloys [4] used as core material in distribution transformers. A promising application of these materials concerns also the exploitation of their magnetoelastic properties to be employed in sensors [5-6] and bio-sensors [7]. Moreover the properties can be improved by tuning the composition of the alloy with the addition of other elements, therefore this ternary system is an important basis for more complex glass-forming alloys [8]. Examples include FINEMET, a nanocrystalline alloy with good soft magnetic properties obtained by adding to the Fe-Si-B system Copper and Niobium, while amorphous steels [9] are promising non magnetic Bulk Metallic Glasses with exceptional strength.

Amorphous alloys are metastable and it is well known that Fe-Si-B metallic glasses, similarly to binary Fe-B ones, crystallize in two different ways forming a mixture of $b c c \mathrm{Fe}$ with either the metastable $\mathrm{Fe}_{3} \mathrm{~B}$ phase or the stable $\mathrm{Fe}_{2} \mathrm{~B}$ one according to the metalloid content [10]. Moreover it is worthwhile to underline that $\mathrm{Fe}_{3} \mathrm{~B}$ can nucleate during quenching and competes with the formation of the glass. The ability of the alloy to glass formation is highest in the composition range where a metastable ternary eutectic is supposed to occur [11]. The above reasons motivate the interest in the metastable equilibria of this ternary system exploiting the potential of the Calphad method. 
In the literature the most recent assessment of the ternary $\mathrm{Fe}-\mathrm{Si}$ - $\mathrm{B}$ system has been provided, also using own experimental data, by Tokunaga [1] comparing the results with the ternary equilibria found experimentally by Aronsson [12], Efimov [13] and Chaban [14]. Although the issue of glass formation is clearly raised in [1], the metastable $\mathrm{Fe}_{3} \mathrm{~B}$ phase was not taken into account. On the other hand, Palumbo [2] provided an assessment of the binary Fe-B system comprehensive of both the stable and the metastable phase diagrams involving either $\mathrm{Fe}_{2} \mathrm{~B}$ or $\mathrm{Fe}_{3} \mathrm{~B}$. In this work we propose an improvement of the description of the $\mathrm{Fe}-\mathrm{Si}-\mathrm{B}$ proposed by Tokunaga introducing the metastable $\mathrm{Fe}_{3} \mathrm{~B}$ compound in the Calphad description of the ternary system.

Furthermore, a treatment of the glass transition has been implemented both in the binary $\mathrm{Fe}-\mathrm{B}$ and in the ternary Fe-Si-B systems according to the model proposed by Shao [15] where the amorphous phase is described by using the formalism developed by Hillert and Jarl [16] for the ferromagnetic transitions. This model also allows to consider the composition dependence of the glass transition temperature, $\mathrm{T}_{\mathrm{g}}$, and the introduction of experimental data on crystallization in the assessment process. In [2] the glass transition was already treated fixing the $\mathrm{T}_{\mathrm{g}}$ at $800 \mathrm{~K}$ for every composition while in [1] the glass transition was not dealt with. Shao's model allows, although with some limitations, to model the heat capacity of the undercooled liquid in the region above $\mathrm{T}_{\mathrm{g}}$, reflecting the increase in short range order in the undercooled liquid needed for the formation of the glass.

\section{Thermodynamic model}

\subsection{Solution phases and stoichiometric compounds}

Aronsson [12], Efimov [13] and Chaban [14] studied the Fe-Si-B equilibria finding three ternary compounds: $\mathrm{Fe}_{5} \mathrm{Si}_{2} \mathrm{~B}, \mathrm{Fe}_{4.7} \mathrm{SiB}_{2}$ and $\mathrm{Fe}_{2} \mathrm{Si}_{0.4} \mathrm{~B}_{0.6}$. In this study all these are described as stoichiometric phases expressing their free energy according to the formula:

${ }_{G}^{F e} e_{a} S i_{b} B{ }_{c=a} \cdot{ }^{0} G b c c, F e_{+} b \cdot{ }_{G}{ }_{G}$ diamond,$S i_{+c} \cdot{ }_{G}{ }^{\beta-r h o m b o h e d r a l, B+\Delta G f, F e} e_{a} i_{b} B_{c}$

where ${ }^{0} G^{b c c, F e},{ }^{0} G^{\text {diamondc,Si }}$ and ${ }^{0} G^{\text {b-rhombohedralc,B }}$ are the lattice stability of the reference state respectively for $\mathrm{Fe}, \mathrm{Si}$ and $\mathrm{B}$.

The formation energy per mole of unit formula, $\Delta G f, F e_{a} S i_{b}{ }_{c}$, is expressed by:

$$
\Delta G f, F e_{a} S i_{b} B_{c}=A+B \cdot T
$$

being A and B the enthalpy and the entropy of formation.

The Gibbs free energy of $f c c$ and the $b c c$ solid solutions and of the liquid are treated according to the conventional sub-regular solution model:

$$
\begin{aligned}
& G={ }^{r e f} f_{G+}{ }^{i d_{G+}}{ }^{e x} G \\
& { }^{r e f} G=x_{B} \cdot{ }^{0} G^{\phi}{ }_{B}+x_{F e} \cdot{ }^{0} G^{\phi}{ }_{F e}+x_{S i} \cdot{ }^{0} G^{\phi} S i \\
& { }^{i d} G=R T \cdot\left(x_{B} \cdot \ln x_{B}+x_{F e} \cdot \ln x_{F e}+x_{S i} \cdot \ln x_{S i}\right)
\end{aligned}
$$


${ }^{e x} G=x_{B} x_{F e} \cdot{ }^{\phi} L_{B, F e}+x_{F e} x_{S i} \cdot{ }^{\phi} L_{F e, S i}+x_{B} x_{S i} \cdot L_{B, S i}+x_{B} x_{F e} x_{S i} \cdot{ }^{\phi} L_{B, F e, S i}$

Where ${ }^{0} G_{i}$ denotes the Gibbs free energy of the element $i$ in the $\phi$ phase, $x_{i}$ the molar fraction of the element $i$ and $\mathrm{R}$ is the gas constant. The excess free energy ${ }^{e x} G$ has been expressed with the Redlich-Kister-Muggianu polynomial and ${ }^{\phi} L_{A, B}, \quad{ }^{\phi} L_{A, B, C}$ (Tab. 3) stand for the interaction parameters for the binary and ternary systems. The ${ }^{0} G_{i}$ has been taken from SGTE data file [17]. A parameter of ternary interaction has been used in the description of the liquid but not for the ternary $f c c$ and $b c c$ solid solutions.

\subsection{Accounting for the glass transition}

In the temperature range from the glass transition temperature up to the melting point glass-formers display an excess heat capacity related to ordering at short range in the undercooling regime (expressed by both the associate solution model and the two state model [18-19]). Palumbo [2] proposed to model the glass transition as a second order one; this can be justified by the consideration that the behavior of the extensive and differential thermodynamic properties during it agree with Ehrenfest's classification of thermodynamic transitions [20]. Of course the amorphous phase cannot be considered as sitting in a single minimum in the free energy landscape of a multicomponent system but a wealth of local minima must be envisaged. Therefore, the glass transition temperature depends on the cooling rate and can be better defined as a range of temperatures where the formation of a glassy state occurs. With the aim to build a model capable of fitting experimental data in an assessment process, it can be assumed that the ordering in the undercooled liquid occurs until the entropy of the solid phase and that of the liquid are the same (Kauzmann paradox) at the Kauzmann temperature, $\mathrm{T}_{\mathrm{K}}$. Although this temperature point cannot be detected in experiments, it provides a thermodynamic definition of the glass transition temperature. In the framework of CALPHAD a formalism is used since long to represent second order transitions of the ferromagnetic type. Shao first proposed to employ such formalism as a tool to deal with the amorphous phase in an assessment process and applied it successfully to several systems [21-22]. Also Abe [18] and Palumbo [23] described the glass transition with this model, in association with, respectively, the associate solution model and an excess heat capacity parameter for the undercooled liquid.

In Calphad the ferromagnetic transition is based on the work of Inden [24] who found a good interpolation function of the magnetic contribution to experimental heat capacity $C^{\text {mag,Pc}:}$

$$
\begin{aligned}
& C_{\text {mag, },}=K^{L R O} \cdot \ln \left(\frac{1+\tau^{3}}{1-\tau^{3}}\right) \quad \tau=\frac{T}{T_{C}} \leq 1 \\
& C^{\text {mag, }, p}=K^{S R O} \cdot \ln \left(\frac{1+\tau^{-^{5}}}{1-\tau^{-^{5}}}\right) \quad \tau=\frac{T}{T_{C}}>1
\end{aligned}
$$

with $\mathrm{T}_{\mathrm{c}}$ the Curie temperature and $K^{L R O}, K^{S R O}$ empirically derived constants. 
Hillert and Jarl [16] later proposed an expression for the magnetic contribution by a series expansion of Inden formulae according to which the magnetic contribution to free energy, $G_{m a g}$, due to the stabilization of ferromagnetic state with respect to the paramagnetic one is expressed through two interpolation functions, one below and the other above the Curie temperature:

$$
\begin{aligned}
G_{\text {mag }} & =R T \cdot \ln (\alpha+1) \cdot g(\tau) \\
g(\tau) & =\left\{1-\left[\frac{79 \cdot \tau^{-1}}{140 \cdot p}+\frac{474}{497}\right] \cdot\left(\frac{1}{p}-1\right) \cdot\left(\frac{\tau^{3}}{6}+\frac{\tau^{9}}{135}+\frac{\tau^{15}}{600}\right)\right\} / D \quad \tau=\frac{T}{T c} \leq 1 \\
g(\tau) & =\left\{\left(\frac{\tau^{-5}}{10}+\frac{\tau^{-15}}{315}+\frac{\tau^{-25}}{1500}\right)\right\} / D \quad \tau=\frac{T}{T c}>1 \\
D & =\frac{518}{1125}+\frac{11692}{159575} \cdot\left(\frac{1}{p}-1\right)
\end{aligned}
$$

The value of the function $g(\tau)$ depends on the Curie temperature, $T_{c}$, and the parameter $p$ represents the fraction of magnetic enthalpy absorbed above $T_{c}$ [25]. Its value is structure dependent and was given the value 0.43 for a $b c c$ structure, otherwise it was taken as 0.28 .

According to the model proposed by Shao the glass transition temperature is assimilated to the Curie temperature and the free energy difference between the liquid and the amorphous phase as the stabilization due to the ferromagnetic-paramagnetic state. Following the above discussion, here $\mathrm{T}_{\mathrm{c}}$ is set at the Kauzmann temperature. The Kauzmann temperature and the $\alpha$ stabilization parameter are obtained through a RedlichKister expansion using the PARROT module:

$$
\begin{aligned}
& T^{i, j}{ }_{K}=x_{i} \cdot T^{j}{ }_{K}+x^{j} \cdot T^{j}{ }_{K}+x^{i} \cdot x^{j}\left\lfloor\Omega^{i, j}{ }_{0}+\Omega^{i, j}{ }_{1}\left(x^{i}-x^{j}\right)+\Omega^{i, j}{ }_{2}\left(x^{i}-x^{j}\right)^{2}\right\rfloor \\
& \alpha^{i, j}=x_{i} \cdot \alpha^{j}+x^{j} \cdot \alpha^{j}+x^{i} \cdot x^{j}\left[\Lambda^{i, j}{ }_{0}+\Lambda^{i, j}{ }_{1}\left(x^{i}-x^{j}\right)+\Lambda^{i, j}{ }_{2}\left(x^{i}-x^{j}\right)^{2}\right\rfloor
\end{aligned}
$$

where $\Omega^{i, j}{ }_{v}$ and $\Lambda^{i, j}{ }_{v}$ are the binary interaction parameters to describe the concentration dependence of the stabilization parameter $\alpha$ and $\mathrm{T}_{\mathrm{K}}$.

The values of the stabilization parameter $\alpha$ for the pure elements have been obtained from eqs. (9-11) considering the maximum change in entropy due to the amorphous phase formation:

$$
\Delta S^{\text {liquid-amo }}=-R \ln (1+\alpha)
$$

approximating the maximum change in entropy of pure components with the entropy of melting while $T_{K}$ of pure elements is approximated as $T_{K}=0.25 \mathrm{Tm}$. Data on and correlations of the Kauzman temperature of several amorphous alloys with the glass 
transition temperature and other thermophysical parameters have been recently collected for inorganic, organic and metallic glasses [26]. A relationship between $T_{K}$ and $T_{g}$ can be proposed as $T_{K}=0.8 T_{g}$. This average value disregards differences in glass forming ability and glass stability of different substances. It, however, provides a simple estimate for $\mathrm{T}_{\mathrm{K}}$ and will be justified a posteriori by the results of assessment.

The choice of the $p$ parameter in the ferromagnetic formalism influences the shape of the heat capacity and weights the relative importance of the two interpolation function $g(\tau)$ below and above $\mathrm{T}_{\mathrm{C}}$ : an high value of $p$ means enhancing the role of the function that expresses the heat capacity above $\mathrm{T}_{\mathrm{c}}$. In our study the value of $p$ is set to 0.99 to exploit the influence of this paramenter on the shape of the heat capacity curve with an abrupt jump at the glass transition. In Fig. 1 supposed heat capacity, $C_{p}$, curves of a binary $\mathrm{Fe}_{80} \mathrm{~B}_{20}$ system for the liquid-amorphous state according to Shao's model are shown for different values of $p: 0.28$, as in a generic ferromagnetic transition, $\mathrm{p}=0.43$, for a ferromagnetic transition in a bcc structure, $p=0.6$, as used by Shao and $p=0.99$, as used in this work.

In the binary and ternary system optimized in this study the amorphous phase has been introduced using as experimental data the enthalpy of crystallization $\Delta \mathrm{H}_{\mathrm{x}}$. This quantity refers to the difference of enthalpy between amorphous and crystalline phases at $T_{x}$, the crystallization temperature. Considering the heat capacity of the amorphous phase equal to that of the crystal phase between $T_{x}$ and $T_{K}$ we associated the experimental $\Delta H_{x}$ to the calculated Kauzmann temperature.

\section{Optimized Results an discussion}

\subsection{Fe-B , Si-B and Fe-Si binary systems}

The thermodynamic parameters for the binary $\mathrm{Fe}-\mathrm{Si}$ and $\mathrm{Si}-\mathrm{B}$ systems were taken from [27] and [28], respectively. The Fe-B system has been assessed several times [2, 29-32], however the amorphous and metastable phases have been treated only by Palumbo [2] although without resorting to the Shao's model for the former. Recently, this work has been used as a starting point to predict the devitrification kinetics of amorphous steel [33]. The Fe-B system used here derives from [2] employing the Shao's model of the glass transition. In the literature the equilibria between $\mathrm{Fe}_{2} \mathrm{~B}, \mathrm{FeB}$ and liquid in the region near the $\mathrm{Fe}_{2} \mathrm{~B}$ boride have been thoroughly discussed. Some authors [34] proposed the occurrence of a eutectic reaction between $\mathrm{FeB}$ and $\mathrm{Fe}_{2} \mathrm{~B}$ at $\mathrm{X}_{\mathrm{B}}=0.38$ while most of the optimizations [2, 29-31] of the binary system have been done considering a peritectic, although the results look uncertain because of the closeness in the free energy of the phases. The work by Palumbo has been reassessed not only introducing the amorphous phase through the Shao model but also trying to obtain a clear peritectic behaviour of $\mathrm{Fe}_{2} \mathrm{~B}$ re-assessing the parameters for the liquid, $\mathrm{FeB}$, bcc solid solution and $\mathrm{Fe}_{3} \mathrm{~B}$ using as experimental data those given in Tab 1 and the Fe enthalpy of mixing from [50]. In [2] the amorphous phase has been introduced by operating on the interaction parameter of the liquid at the same Kauzmann temperature for all compositions: below $\mathrm{T}_{\mathrm{K}}$ the parameter relates to the amorphous phase with no excess contribution to the heat capacity; above $\mathrm{T}_{\mathrm{K}}$ the undercooled liquid is described with an excess coefficient for the heat capacity. The 
parameters of the liquid and the amorphous phases were linked considering the glass transition as a second order transition. In our work the parameters for the liquid have been re-assessed by treating the undercooled liquid according to the model by Shao and accounting for a composition dependence of $T_{K}$. The stabilization parameter of the amorphous phase has been obtained, by means of the PARROT module, using the heats of crystallization. In Fig. 2 and in Fig. 3 results of the re-assessment are presented: in Fig. 2a the calculated and experimental heat of crystallization versus composition are shown; we can see that the calculated data reproduce the trend of the experimental value within the scatter. Also the mixing properties in the liquid phase are in good accordance with the experimental data [32] as shown in Fig. 2b where the calculated and experimental partial molar enthalpies of $\mathrm{Fe}$ as a function of $\mathrm{X}_{\mathrm{B}}$ are shown. The thermodynamic properties of the liquid at high temperature obtained in this re-assessment are compared in Fig. 2c with the activity of $\mathrm{Fe}$ in the Fe-B liquid at $1600{ }^{\circ} \mathrm{C}$ determined by Miki et al. [33]; at $\mathrm{x}_{\mathrm{Fe}}$ higher than 0.7 our assessment overestimates the experimental values similarly to [33], while at lower Fe content the agreement is good. The binary phase diagrams, both stable and metastable are shown in Fig. 3a-b. They are in good accordance with the previous one. In Tab. 1 the calculated and experimental thermodynamic properties used in the optimization in comparision with the results obtained by Palumbo [2] are given. In our assement the eutectic between $\mathrm{Fe}_{2} \mathrm{~B}$ and fcc Fe has been found at $\mathrm{X}_{\mathrm{B}}=0.176$ and $1166{ }^{\circ} \mathrm{C}$, very close to the experimental data obtained in [37] $\left(\mathrm{X}_{\mathrm{B}}=0.170\right.$ and $\left.1164{ }^{\circ} \mathrm{C}\right)$. The peritectic equilibrium between $\mathrm{Fe}_{2} \mathrm{~B}$, liquid and $\mathrm{FeB}$ has been obtained at $1383{ }^{\circ} \mathrm{C}$ and $\mathrm{X}_{\mathrm{B}}=$ 0.333 closer to the experimental data obtained by [38] $\left(\mathrm{X}_{\mathrm{B}}=0.325\right.$ and $\left.1389{ }^{\circ} \mathrm{C}\right)$ than that in [39] $\left(\mathrm{X}_{\mathrm{B}}=0.333\right.$ and $\left.1410{ }^{\circ} \mathrm{C}\right)$. The metastable eutectic between $\mathrm{Fe}_{3} \mathrm{~B}$ and fcc $\mathrm{Fe}$ has been obtained at $\mathrm{X}_{\mathrm{B}}=0.188$ and $1393{ }^{\circ} \mathrm{C}$ close to the experimental data obtained in [37] $\left(\mathrm{X}_{\mathrm{B}}=0.186\right.$ and $\left.1114{ }^{\circ} \mathrm{C} 6\right)$.

\subsection{Optimization of the ternary $\mathrm{Fe}-\mathrm{Si}$-B phase diagram}

The Fe-Si and Si-B binaries are taken, respectively, from the work of [27] and [28] in addition to the binary Fe-B just obtained. In the assessment procedure we optimized the parameters relative to the ternary compounds $\mathrm{Fe}_{5} \mathrm{Si}_{2} \mathrm{~B}, \mathrm{Fe}_{4.7} \mathrm{SiB}_{2}$ and $\mathrm{Fe}_{2} \mathrm{Si}_{0.4} \mathrm{~B}_{0.6}$ and those relative to the ternary interaction parameter of the liquid. The experimental data used are the DSC melting temperatures provided by Tokunaga, the activity measured by Zaitsev [40] and some our DSC data (Tab. 4). The aim of this initial optimization procedure is to obtain the stable ternary phase diagram which results comparable to that obtained by Tokunaga as shown in the isothermal section at $1000{ }^{\circ} \mathrm{C}$ (Fig.4); we just find a smaller two phase $\mathrm{Fe}_{2} \mathrm{Si}_{0.4} \cdot \mathrm{B}_{0.6}$-bcc region with respect to [1]. A good accordance has been obtained also in the isopleth at $\mathrm{X}_{\mathrm{B}}=0.10$ where DSC data were available from Tokunaga, as can be seen in Fig. 5a. On the other hand the section at $\mathrm{X}_{\mathrm{Fe}}=0.65$ (Fig. 5b) at low silicon content is quite different with respect to [1], for concentrations up to $\mathrm{X}_{\mathrm{Si}}=0.15$ : a better description of the liquidus points has been obtained whereas the differences with respect to experimental DSC points regarding the solidus are higher. In Fig. 5c the section at $\mathrm{X}_{\mathrm{Fe}}=0.80$ is shown together with our DSC data: also in this region a good fit to the experimental data has been achieved. In Fig. 6 the calculated and experimental enthalpy of 
mixing of liquid are presented at $\mathrm{X}_{\mathrm{B}}=0.25$ and $1650{ }^{\circ} \mathrm{C}$. The agreement is reasonable up to $\mathrm{X}_{\mathrm{Si}}=0.20$ whereas a larger deviation is found at higher silicon content.

Once the parameters for representing the ternary phase equilibria have been obtained, we introduced the Shao's model for the amorphous and undercooled liquid and optimized the $\alpha$ and $\mathrm{T}_{\mathrm{K}}$ parameters (Eq. 13-14) as above on the basis of experimental data of the heats and temperatures of crystallization [41-43]. For this step accounting for the $\mathrm{Fe}_{3} \mathrm{~B}$ phase is important because of its occurrence as a product of crystallization.

For the Fe-Si-B system there is complete lack of experimental data on the heapacity in the undercooled liquid region and also the glass transition temperature has never been detected because it is preceded by the crystallization of the amorphous phase. Therefore, the Kauzmann temperature has been approximated as in the case of the Fe-B system, using the temperature of crystallization $\mathrm{T}_{\mathrm{x}}$ i. e. $\mathrm{T}_{\mathrm{K}}=0.8 \mathrm{~T}_{\mathrm{x}}$. Only in quaternary Fe-Al-Si-B alloys glass transition is detectable and the heat capacity for the $\mathrm{Fe}_{65} \mathrm{Al}_{7} \mathrm{~B}_{18} \mathrm{Si}_{10}$ composition has been measured [44]. A value of $\mathrm{C}_{\mathrm{p}}{ }^{\text {Liquid }}$ of $43.4 \mathrm{~J} / \mathrm{mol}^{\circ} \mathrm{C}$ has been obtained at $572{ }^{\circ} \mathrm{C}$ in the undercooling regime; the calculated value of $\mathrm{C}_{\mathrm{p}}^{\text {liquid }}$ for the $\mathrm{Fe}_{72} \mathrm{~B}_{18} \mathrm{Si}_{10}$ alloy at the same temperature in this work is $49.9 \mathrm{~J} / \mathrm{mol}^{\circ} \mathrm{C}$, of the same order of the experimental value. Since in most alloys crystallisation occurs as a two steps process to a $b c c$ solid solution first and a compound at higher temperature, the use of the heat of crystallization in the assessment required special care. Two procedures were attempted to obtain the heats of crystallization:

- in the first one we tried to calculate the partial heats of crystallization associated to each step relating them to the respective DSC peak temperature,

- in the second one the overall heat of crystallization was computed assuming an average crystallization temperature in between the two DSC peaks, in view also of the relative proximity of the two peaks.

Although the first procedure would be conceptually more satisfactory, it was not possible to obtain a reasonable fit of the partial heat of crystallization, therefore, we resolved to employ the latter procedure.

In Tab. 2 calculated and experimental heat of crystallization are given for ternary alloys with variable amount of $\mathrm{Fe}$; in general the accordance between experimental and calculated data are good and differences are mostly within $600 \mathrm{~J} / \mathrm{mol}$, i. e. close to the scatter for experimental points. It is important to note that the introduction of the amorphous phase does not change the description of equilibria at high temperature, infact the ternary phase diagrams shown in Fig. 4 and 5 refer to the case where the amorphous phase has already been considered.

The predicted metastable $\mathrm{Fe}-\mathrm{Si}-\mathrm{B}$ phase diagram, obtained by suspending the $\mathrm{Fe}_{2} \mathrm{~B}$ phase, is shown in Fig. 7 for the isothermal section at $1000{ }^{\circ} \mathrm{C}$.

The metastable eutectic of the ternary $\mathrm{Fe}-\mathrm{Si}$ - $\mathrm{B}$ is evidenced in the liquid surface projection of Fig. 8; the region around it is expected to correlate with the easy glass formation by rapid quenching. Actually Hagiwara [45] studied the critical ribbon thickness of Fe-Si-B in a wide range of concentrations finding higher values along the $25 \%$ line with $14-19 \%$ of $\mathrm{B}$. Fig. 9 shows the isopleth at $\mathrm{X}_{\mathrm{Fe}}=0.76$ comprising the ternary eutectic which occurs at the concentration $\mathrm{Fe}_{74} \mathrm{Si}_{8} \mathrm{~B}_{18}$. 


\section{Conclusions}

This paper improves previous assessements of $\mathrm{Fe}-\mathrm{B}$ and $\mathrm{Fe}-\mathrm{Si}-\mathrm{B}$ systems on two grounds:

- $\quad$ the liquid $C_{p}$ down to the glass transition has been modeled by means of the Shao's model with a dependence on both temperature and concentration contrary to [1] and [2],

- the metastable $\mathrm{Fe}_{3} \mathrm{~B}$ compound, a major product of glass crystallization, has been introduced in both binary Fe-B and ternary Fe-Si-B systems.

The main results of this work are:

- the metastable equilibria involving the $\mathrm{Fe}_{3} \mathrm{~B}$ phase in the ternary system have been established finding the ternary metastable eutectic in a concentration range where the highest glass formability has been reported in literature,

- the thermodynamic quantities (partial molar enthalpy of mixing, heat of mixing, heat of crystallization) are well reproduced,

- the functional shape of the liquid $C_{p}$ curve has been adopted to the actual trend down to $\mathrm{T}_{\mathrm{g}}$ by tunning the $p$ parameter of the Shao's model.

\section{Acknowledgements}

This work has been performed in the frame of the EU-7FP project 'ACCMET'. 

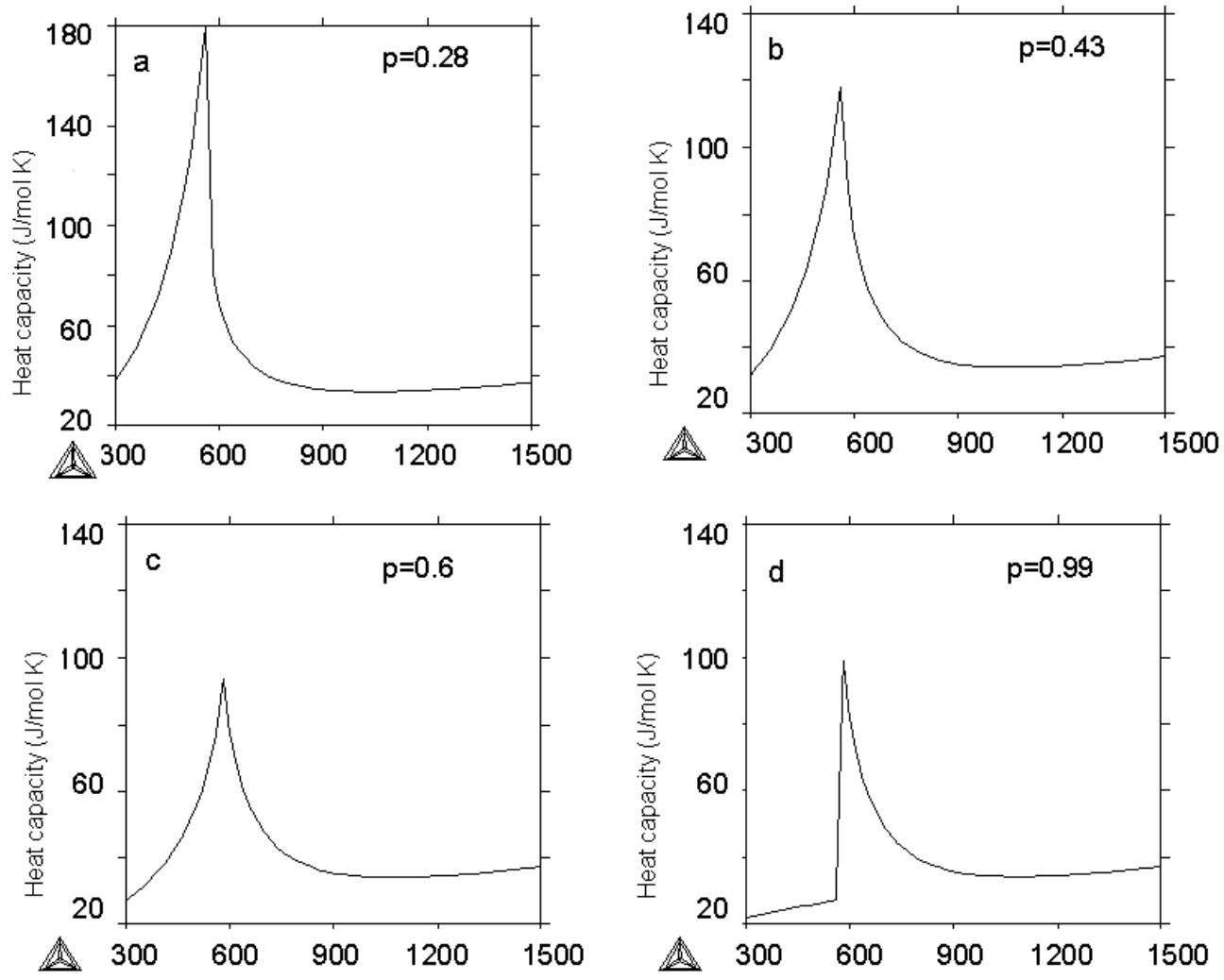

Figure 1: Heat capacity trend of a binary liquid $\mathrm{Fe}_{80} \mathrm{~B}_{20}$ alloy according to Shao's model with different values of the $p$ parameter. 


\begin{tabular}{|c|c|c|c|c|c|c|c|c|}
\hline \multirow[t]{2}{*}{ Comp. } & \multirow[t]{2}{*}{ Property } & \multicolumn{2}{|c|}{ Reference phase } & \multirow[t]{2}{*}{$\mathrm{T}\left({ }^{\circ} \mathrm{C}\right)$} & \multirow{2}{*}{$\begin{array}{l}\text { Calculated } \\
\text { (J/mol of } \\
\text { atoms) }\end{array}$} & \multirow{2}{*}{$\begin{array}{l}\text { Palumbo [2] } \\
\begin{array}{l}\text { (J/mol of } \\
\text { atoms) }\end{array}\end{array}$} & \multirow{2}{*}{$\begin{array}{c}\text { Experimental } \\
(\mathrm{J} / \mathrm{mol} \text { of } \\
\text { atoms })\end{array}$} & \multirow[t]{2}{*}{ Ref } \\
\hline & & $\mathrm{Fe}$ & $B$ & & & & & \\
\hline \multirow{4}{*}{$\mathrm{Fe}_{2} \mathrm{~B}$} & Enthalpy of formation & $\alpha$ & $\beta$ & 25 & -20970 & -21000 & -22300 & {$[46]$} \\
\hline & Enthalpy of formation & $\gamma$ & $\beta$ & 1112 & -26300 & -26344 & -22600 & [47] \\
\hline & Gibbs energy of formation & $\alpha$ & $\beta$ & 900 & -25580 & -25600 & -26000 & [48] \\
\hline & Gibbs Energy of formation & $\alpha$ & $\beta$ & 827 & -25600 & -25600 & -26400 & [49] \\
\hline \multirow{6}{*}{$\mathrm{cFeB}$} & Enthalpy of formation & $\alpha$ & $\beta$ & 25 & -32400 & -29600 & -35600 & {$[46]$} \\
\hline & Enthalpy of formation & $\gamma$ & $\beta$ & 1112 & -36400 & -33600 & -32300 & {$[47]$} \\
\hline & Gibbs energy of formation & $\alpha$ & $\beta$ & 900 & -32700 & -31600 & -31800 & [48] \\
\hline & Gibbs Energy of formation & $\alpha$ & $\beta$ & 827 & -32940 & -31700 & -33300 & [42] \\
\hline & Enthalpy of fusion & - & - & 1590 & 37600 & 38600 & 31600 & [50] \\
\hline & $\begin{array}{l}\text { Entropy } \\
\text { of } \\
\text { formation }\end{array}$ & - & - & 25 & $\begin{array}{c}17.96 \\
(\mathrm{~J} / \mathrm{mol} \text { of } \\
\left.\text { atoms }{ }^{\circ} \mathrm{C}\right)\end{array}$ & $\begin{array}{c}19.4 \\
(\mathrm{~J} / \mathrm{mol} \text { of } \\
\left.\text { atoms }{ }^{\circ} \mathrm{C}\right)\end{array}$ & $\begin{array}{c}18.1 \\
(\mathrm{~J} / \mathrm{mol} \text { of } \\
\left.\text { atoms }{ }^{\circ} \mathrm{C}\right)\end{array}$ & [50] \\
\hline $\mathrm{Fe}_{3} \mathrm{~B}$ & Enthalpy of formation & $\gamma$ & $\beta$ & 1112 & -18500 & -18300 & -17840 & [37] \\
\hline
\end{tabular}

Tab 1: Calculated and experimental thermodynamic properties of intermetallic compounds in Fe-B system obtained in this optimization and in [2]. 

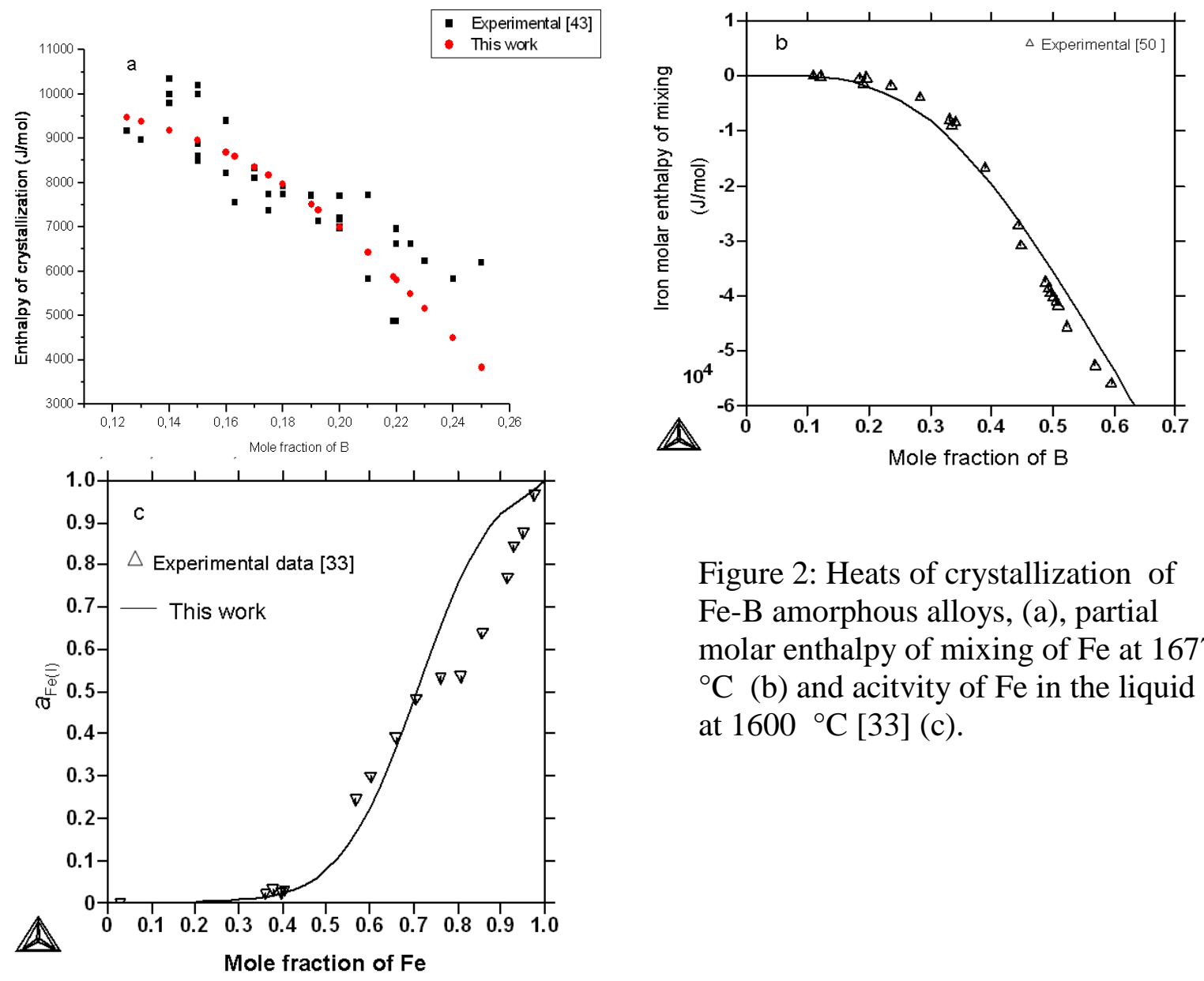

Figure 2: Heats of crystallization of Fe-B amorphous alloys, (a), partial molar enthalpy of mixing of $\mathrm{Fe}$ at 1677 ${ }^{\circ} \mathrm{C}$ (b) and acitvity of $\mathrm{Fe}$ in the liquid at $1600{ }^{\circ} \mathrm{C}$ [33] (c). 

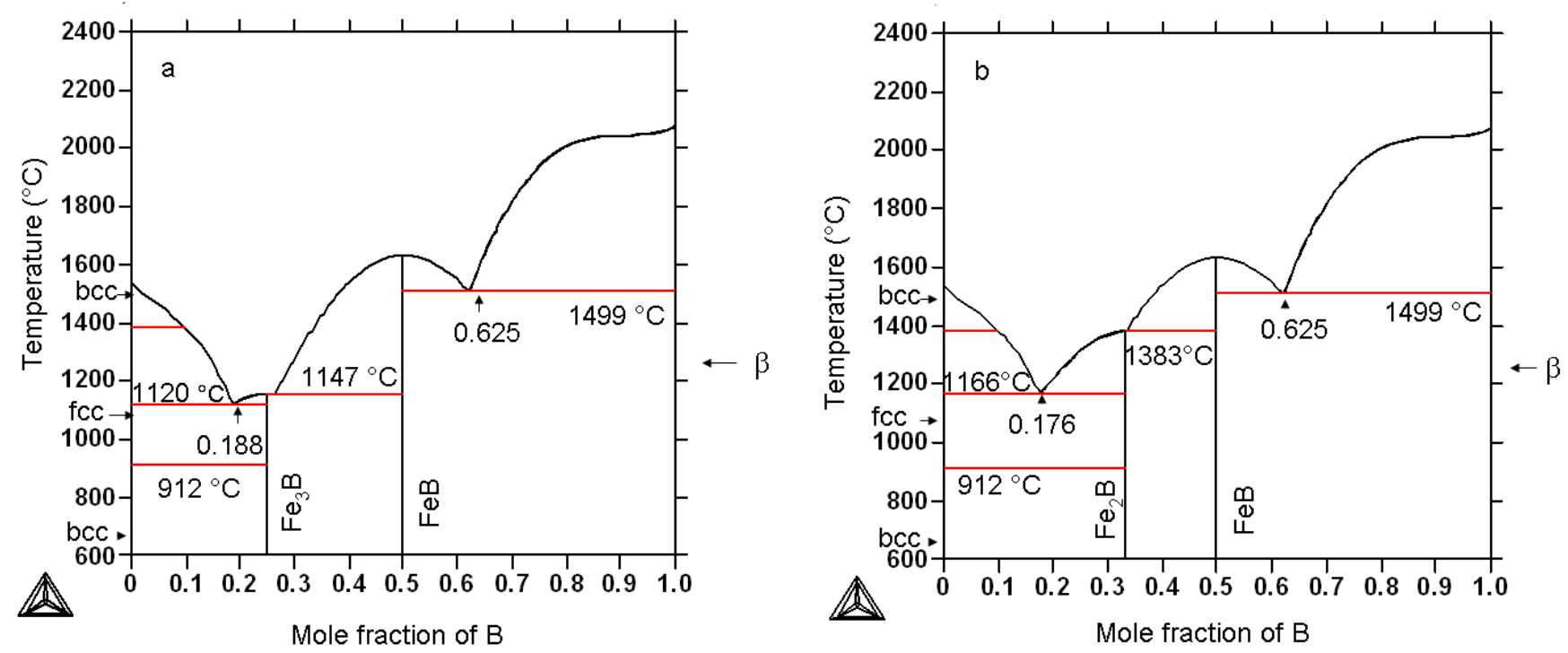

Figure 3 : Optimized metastable (a) and stable (b) Fe-B phase diagrams. 


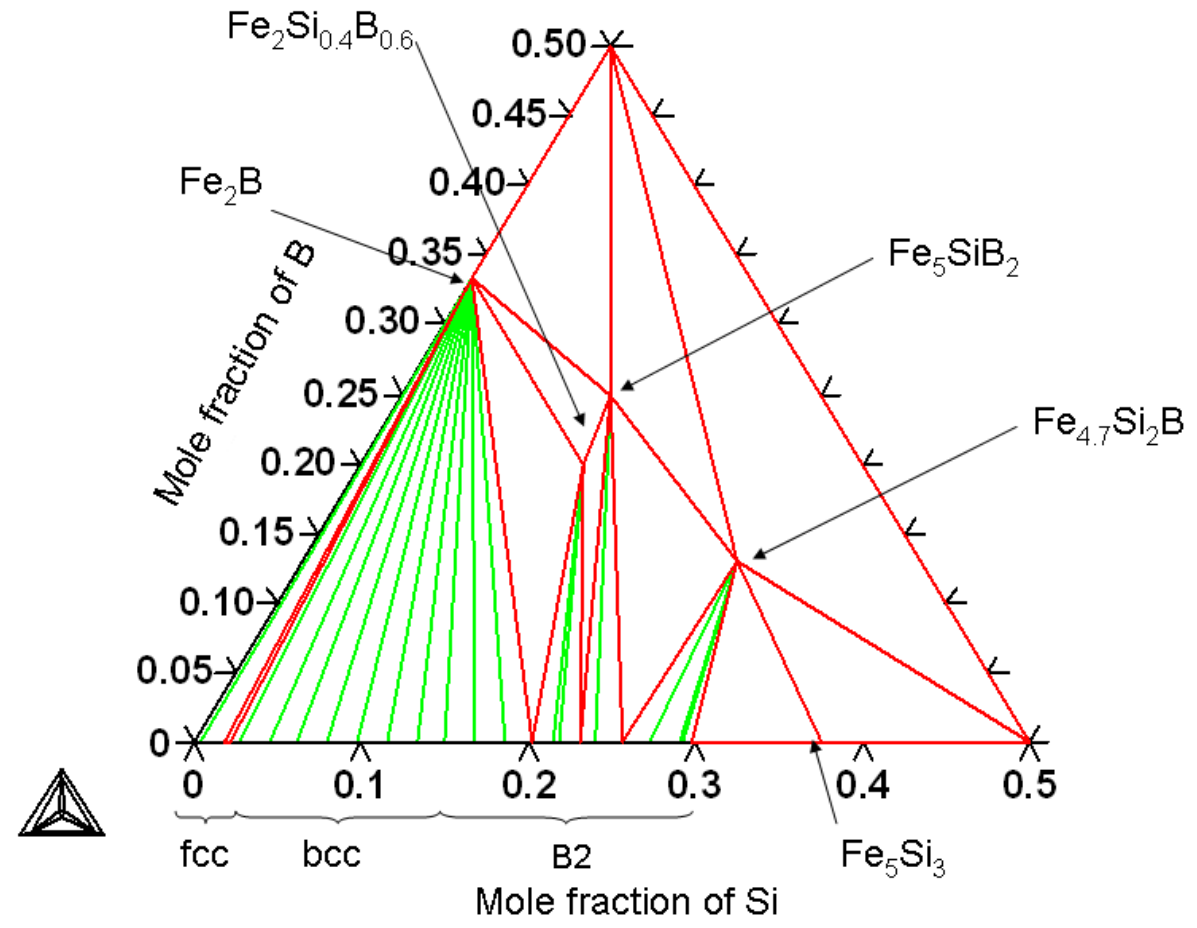

Figure 4 : Isothermal section of the stable $\mathrm{Fe}-\mathrm{Si}-\mathrm{B}$ phase diagram at $1000^{\circ} \mathrm{C}$. 

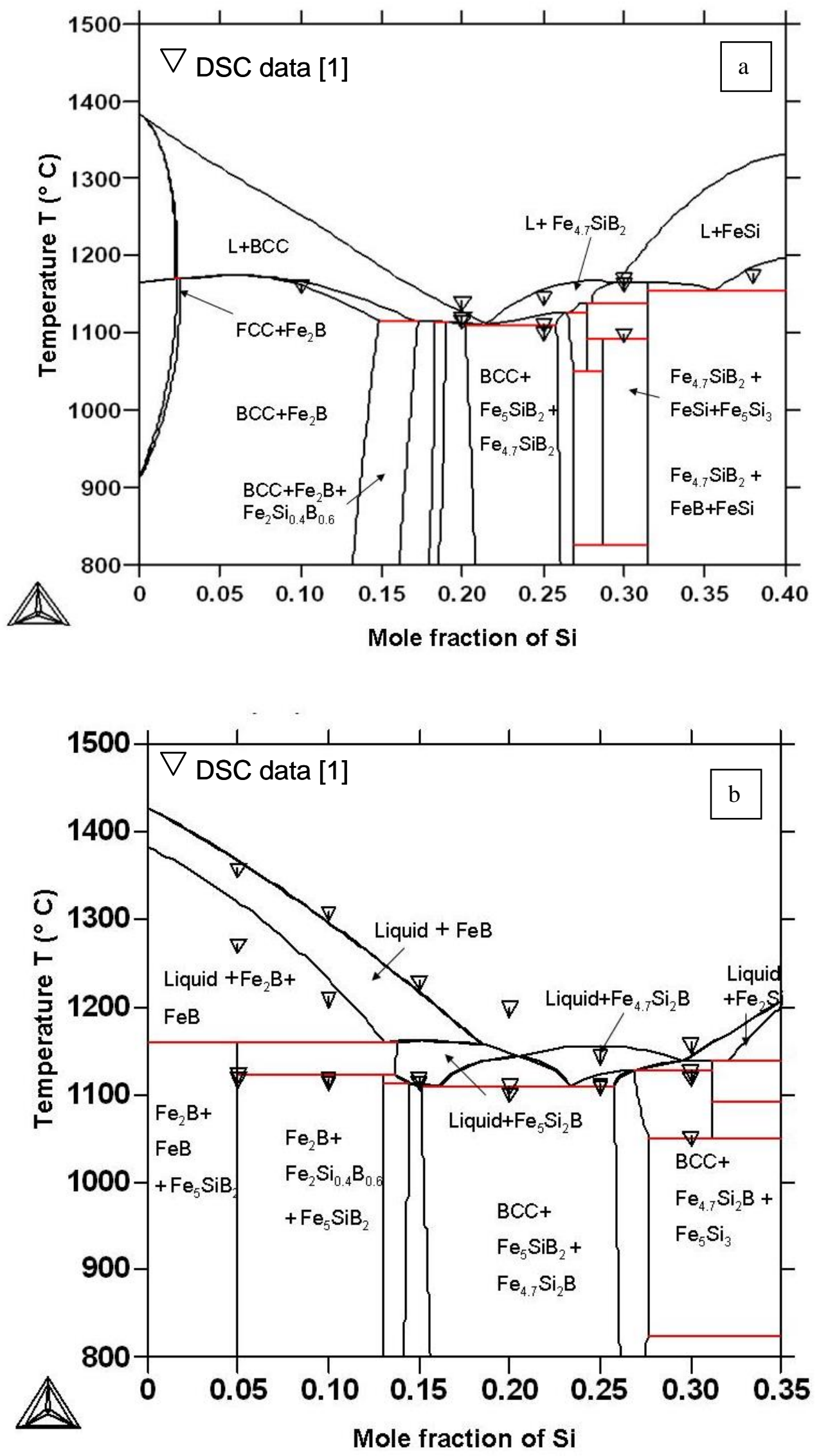


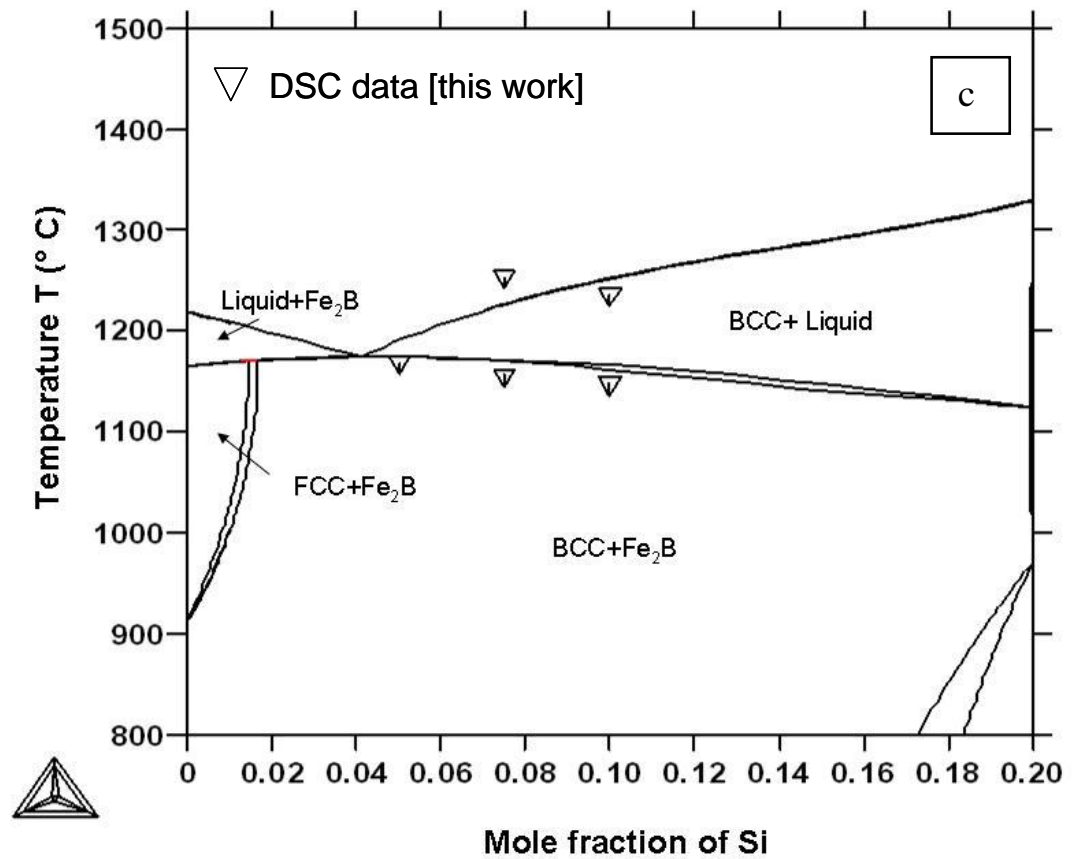

Figure 5 : Calculated isopleths at $X_{\mathrm{B}}=0.10(\mathrm{a})$, at $\mathrm{X}_{\mathrm{Fe}}=0.65(\mathrm{~b})$ with DSC data by [1]. Isopleth at $X_{\mathrm{Fe}}=0.80$ (c) with our DSC data. 


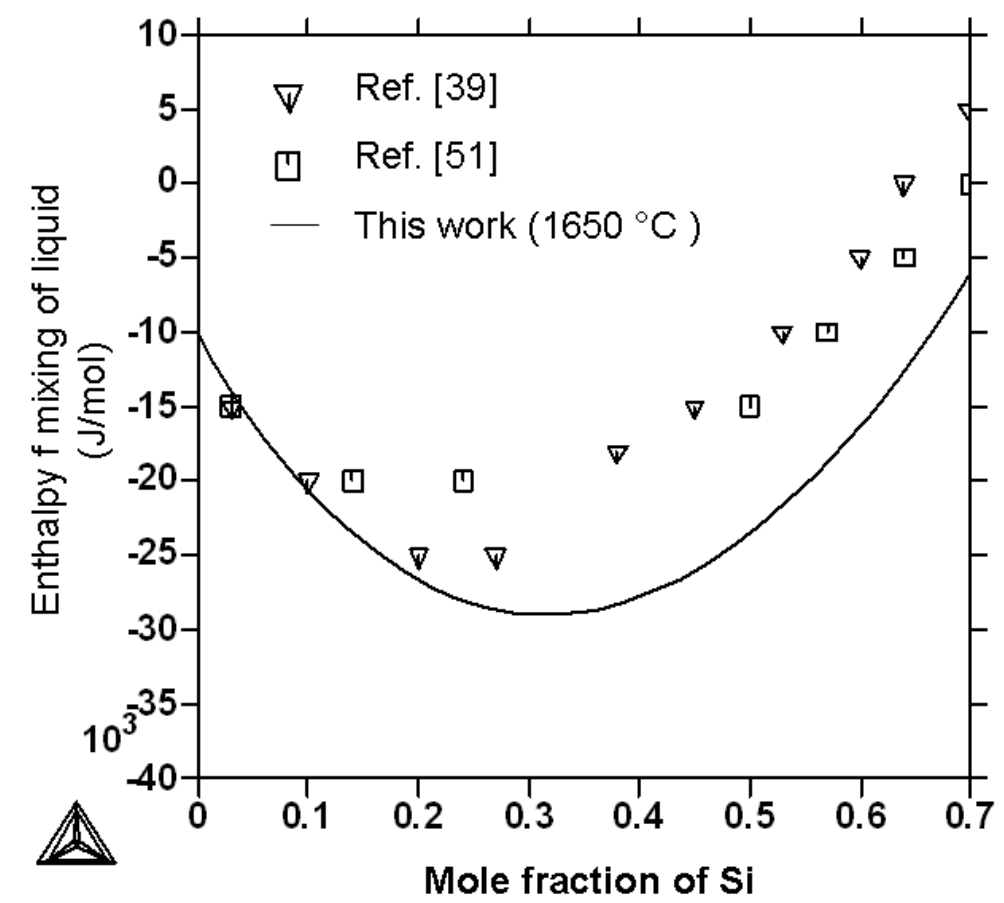

Figure 6: Enthalpy of mixing of the liquid at $\mathrm{X}_{\mathrm{B}}=0.25$ and $1550^{\circ} \mathrm{C}$ and experimental data (reference for boron is $\beta$ rhombohedral) 


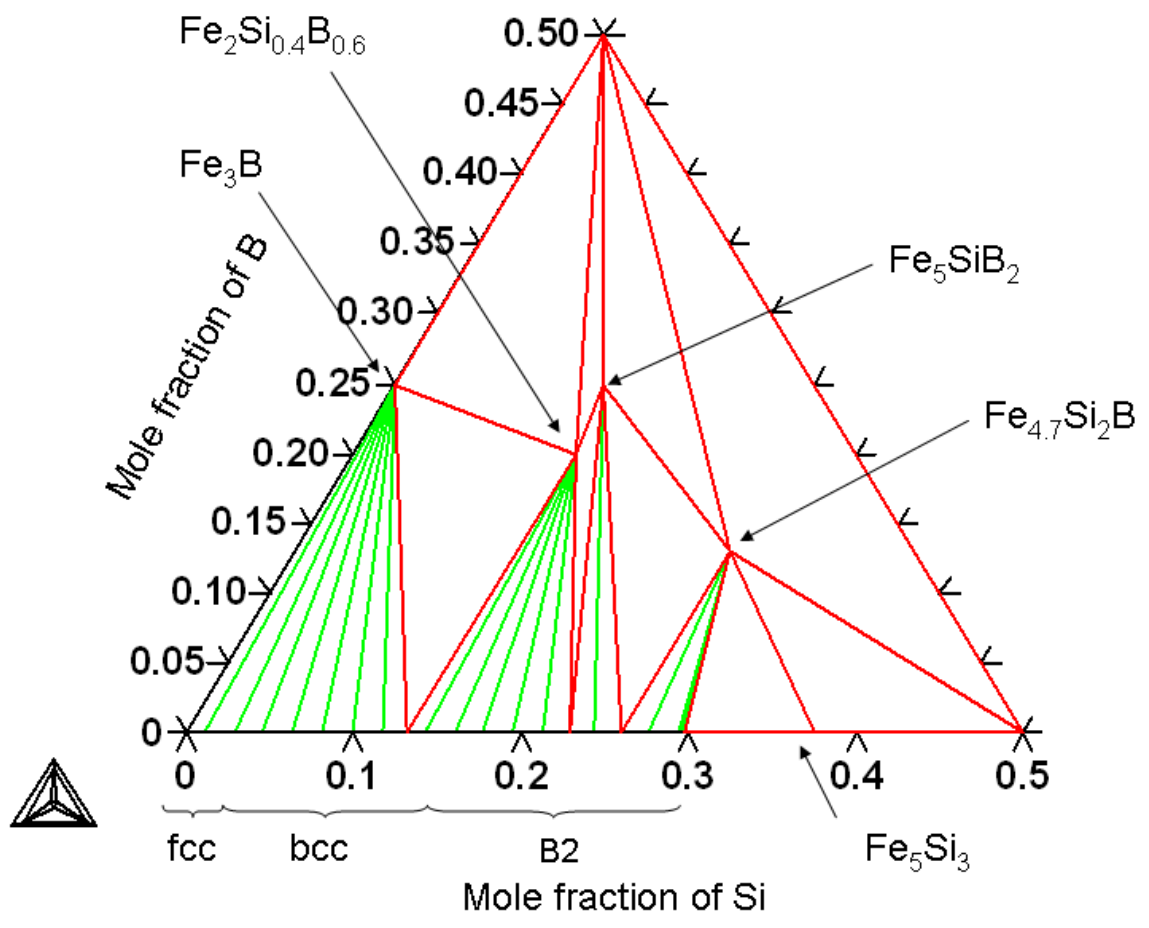

Figure 7 : Isothermal section of the metastable ternary Fe-Si-B phase diagram at $1000^{\circ} \mathrm{C}$. 


\begin{tabular}{|c|c|c|c|c|c|c|}
\hline $\mathbf{X}(\mathbf{F e})$ & $\mathbf{X}(\mathbf{B})$ & $\mathbf{X}(\mathbf{S i})$ & $\begin{array}{c}\text { Exp. } \\
\Delta \mathbf{H}(\mathbf{J} / \mathbf{m o l})\end{array}$ & $\begin{array}{c}\text { Calc. } \\
\Delta \mathbf{H}(\mathbf{J} / \mathbf{m o l})\end{array}$ & $\begin{array}{c}\text { Exp. } \\
\left.\mathbf{T}_{\mathbf{X}}{ }^{\circ} \mathbf{C}\right)\end{array}$ & $\mathbf{R e f .}$ \\
\hline 0.75 & 0.1 & 0.15 & 5629 & 5763 & 548 & {$[41]$} \\
\hline 0.78 & 0.13 & 0.09 & 7470 & 7370 & 542 & {$[42]$} \\
\hline 0.8 & 0.18 & 0.02 & 6653 & 6749 & 493 & {$[41]$} \\
\hline 0.8 & 0.16 & 0.04 & 7463 & 8057 & 515 & {$[41]$} \\
\hline 0.8 & 0.12 & 0.08 & 7330 & 7309 & 538 & {$[41]$} \\
\hline 0.8 & 0.1 & 0.1 & 6896 & 7263 & 539 & {$[41]$} \\
\hline 0.8 & 0.14 & 0.06 & 7612 & 7580 & 532 & {$[41]$} \\
\hline 0.805 & 0.173 & 0.022 & 6900 & 6805 & 487 & {$[43]$} \\
\hline 0.805 & 0.129 & 0.066 & 8700 & 8518 & 517 & {$[43]$} \\
\hline 0.81 & 0.106 & 0.084 & 7790 & 7312 & 537 & {$[43]$} \\
\hline 0.81 & 0.085 & 0.105 & 7700 & 7625 & 527 & {$[43]$} \\
\hline
\end{tabular}

Tab 2: Enthalpy and temperature of crystallization of the amorphous $\mathrm{Fe}-\mathrm{Si}$-B phase calculated in this work and experimental [41], [42], [43]. 


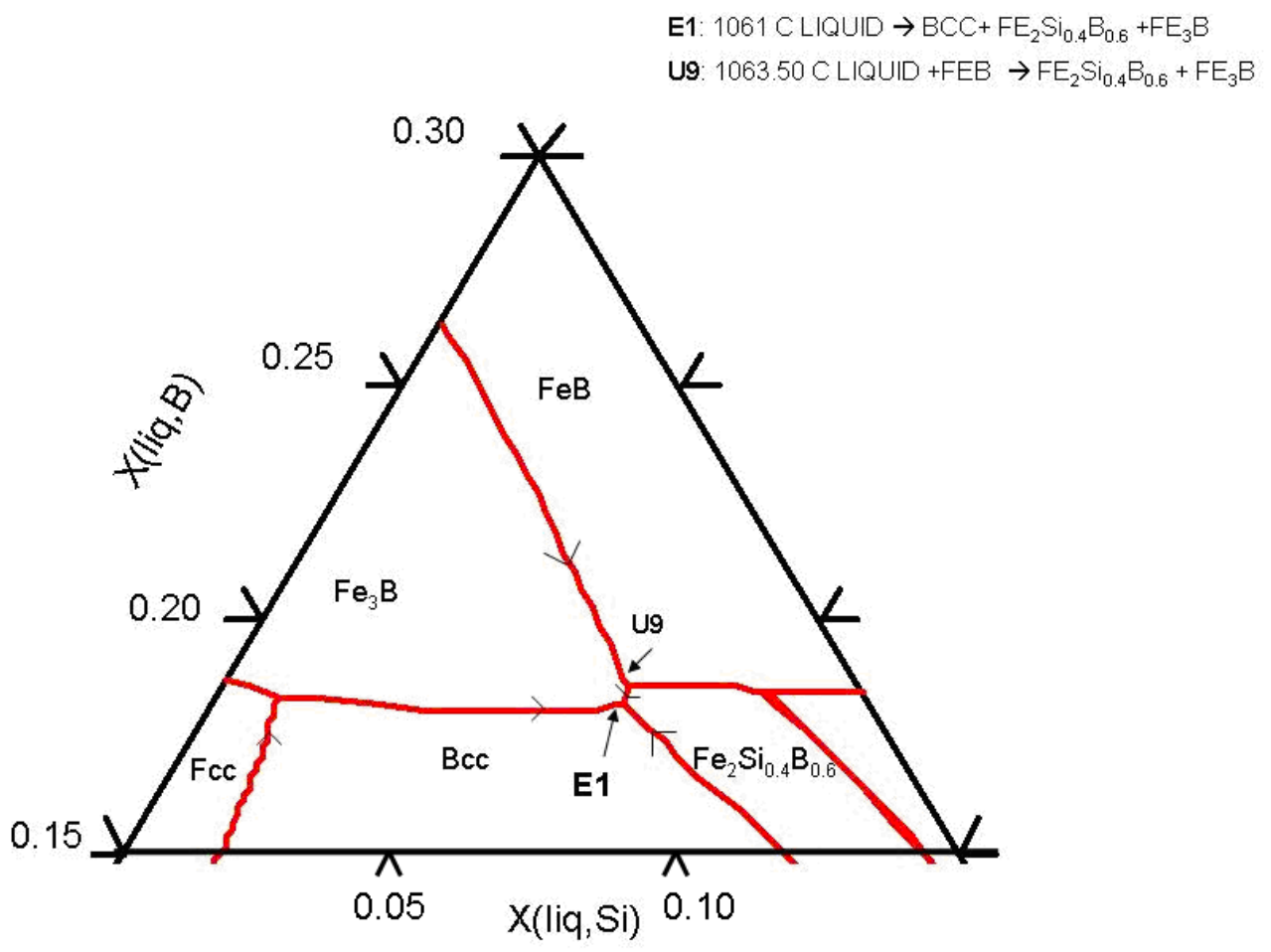

Figure 8: Liquid surface projection of the metastable Fe-Si-B system in the zone near the ternary eutectic $(\mathrm{E} 1)$. 


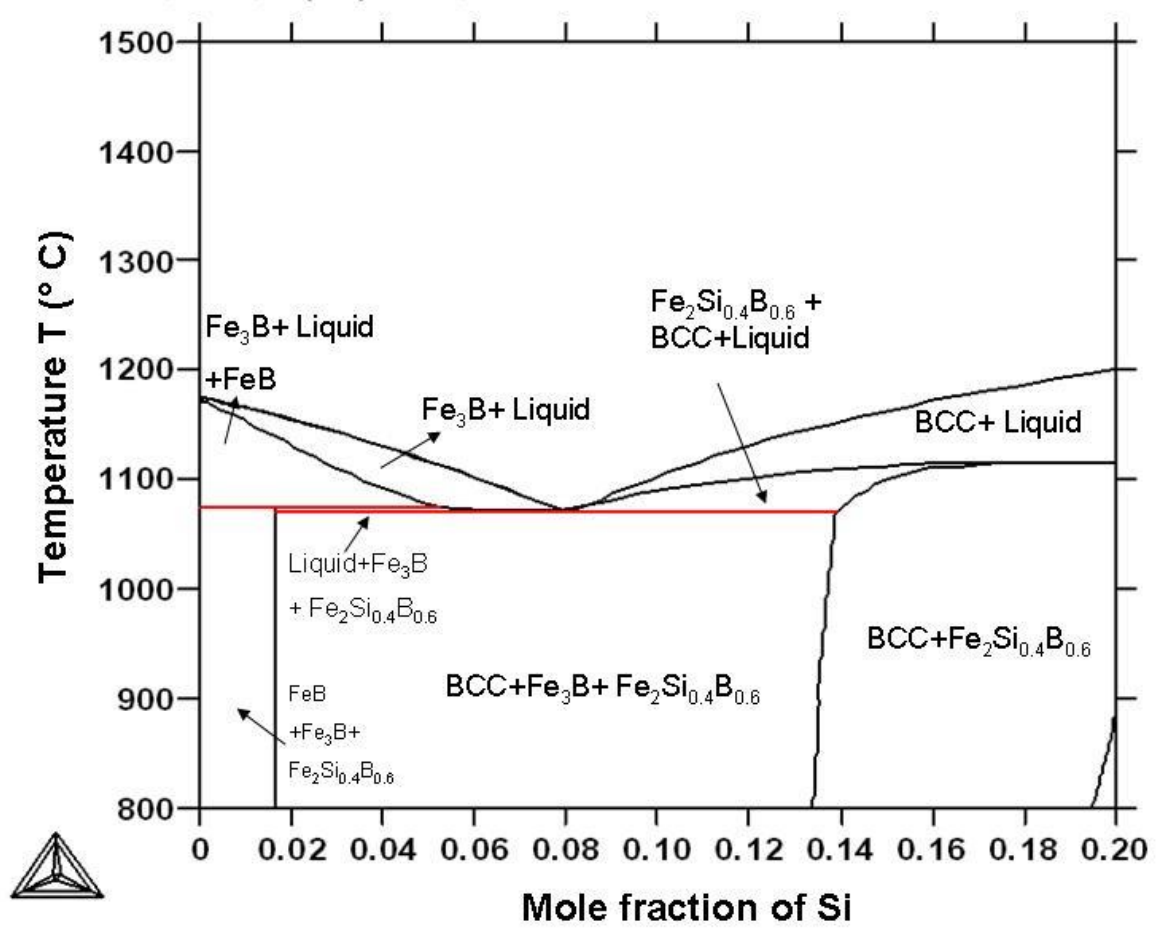

Figure 9: Calculated isopleth at $\mathrm{X}_{\mathrm{Fe}}=0.74$ where the ternary metastable eutectic is evidenced at $1061{ }^{\circ} \mathrm{C}, \mathrm{X}_{\mathrm{B}}=0.18$ and $\mathrm{X}_{\mathrm{Si}}=0.8$. 


\begin{tabular}{|c|c|c|c|c|c|}
\hline Phase & \multicolumn{2}{|c|}{ Parameter (J/mol) } & \multicolumn{3}{|c|}{ Amorphous phase parameter } \\
\hline \multirow[t]{7}{*}{ Liquid } & ${ }^{0} L_{\mathrm{B}, \mathrm{Fe}}^{\mathrm{L}}$ & $-122861+14.59^{*} \mathrm{~T}$ & $\Lambda_{0}^{B, r e}$ & $394 \alpha_{g}{ }^{\mathrm{Fe}}$ & 1.05 \\
\hline & ${ }^{1} L_{\mathrm{B}, \mathrm{Fe}}^{\mathrm{L}}$ & 19523 & $\Lambda_{1}^{\mathrm{B}, \mathrm{re}}$ & $1152 \alpha_{g}^{\mathrm{Si}}$ & 34.09 .00 \\
\hline & ${ }^{2} L_{B, F e}^{L}$ & 51070 & $\Lambda_{2}^{\mathrm{B}, \mathrm{re}}$ & $870 \alpha_{g}{ }^{B}$ & 12 \\
\hline & ${ }^{0} L_{\mathrm{B}, \mathrm{Fe}, \mathrm{Si}}^{\mathrm{L}}$ & 0 & $\Lambda_{0}^{\mathrm{B}, \mathrm{re}, \mathrm{Si}}$ & $-2039 \mathrm{~T}_{\mathrm{g}}^{\mathrm{re}}$ & 452.07 .00 \\
\hline & ${ }^{7} L^{\mathrm{L}}{ }_{\mathrm{B}, \mathrm{Fe}, \mathrm{Si}}$ & -55686 & $\Lambda_{1}^{\mathrm{B}, \mathrm{re}, \mathrm{Si}}$ & $662 \mathrm{~T}_{\mathrm{g}}^{\mathrm{Si}}$ & 422 \\
\hline & ${ }^{2} L_{\mathrm{B}, \mathrm{Fe}, \mathrm{Si}}^{\mathrm{L}}$ & 93217 & $\Lambda_{2}^{\mathrm{B}, \mathrm{re}, \mathrm{SI}}$ & $-3483 \mathrm{~T}_{\mathrm{g}}^{\mathrm{B}}$ & 587.25 .00 \\
\hline & & & $\Omega_{0}^{\mathrm{B}, \mathrm{Fe}}$ & 1.06 .00 & \\
\hline \multirow[t]{2}{*}{$\mathrm{Fe}_{5} \mathrm{SiB}_{2}$} & $\bar{A}$ & -269801 & $\Omega_{0}^{\mathrm{B}, \mathrm{Fe}, \mathrm{Si}}$ & -77049 & \\
\hline & B & 23.59 & $\Omega_{1}^{\mathrm{B}, \mathrm{re}, \mathrm{SI}}$ & 40437 & \\
\hline \multirow[t]{2}{*}{$\mathrm{Fe}_{4.7} \mathrm{Si}_{2} \mathrm{~B}$} & $\bar{A}$ & -248130 & $\Omega_{2}^{\mathrm{B}, \mathrm{Fe}, \mathrm{Si}}$ & -59909 & \\
\hline & B & 5 & & & \\
\hline \multirow[t]{2}{*}{$\mathrm{Fe}_{2} \mathrm{Si}_{0.4} \mathrm{~B}_{0.6}$} & $\bar{A}$ & -92665 & & & \\
\hline & B & 0,296527778 & & & \\
\hline $\mathrm{BCC}$ & ${ }^{0} L_{\mathrm{B}, \mathrm{Fe}}^{\mathrm{BCC}}$ & $-33092+15.6^{*} T$ & & & \\
\hline \multirow[t]{2}{*}{$\mathrm{FeB}$} & $\bar{A}$ & -73933 & & & \\
\hline & B & 0,307638889 & & & \\
\hline \multirow[t]{2}{*}{$\mathrm{Fe}_{2} \mathrm{~B}$} & $\bar{A}$ & -81226 & & & \\
\hline & B & 3.01 & & & \\
\hline \multirow[t]{2}{*}{$\mathrm{Fe}_{3} \mathrm{~B}$} & $\bar{A}$ & -77749 & & & \\
\hline & B & 2.59 & & & \\
\hline
\end{tabular}

Tab 3 Assessed parameters of the ternary Fe-Si-B system.

\begin{tabular}{|c|c|c|c|}
\hline Composition & Transf. & $\mathrm{T}\left({ }^{\circ} \mathrm{C}\right)$ & \multirow{H}{*}{$\mathrm{H}(\mathrm{J} / \mathrm{mol})$} \\
\hline \multirow{2}{*}{$\mathrm{Fe}_{78} \mathrm{Si}_{2} \mathrm{~B}_{20}$} & Eutectic & 1166 & \multirow{2}{*}{15666} \\
\cline { 2 - 3 } & Liquidus & 1289 & 16293 \\
\hline $\mathrm{Fe}_{80} \mathrm{Si}_{5} \mathrm{~B}_{15}$ & Melting & 1168.5 & \multirow{2}{*}{14892} \\
\hline \multirow{2}{*}{$\mathrm{Fe}_{80} \mathrm{Si}_{7.5} \mathrm{~B}_{12.5}$} & Eutectic & 1144 & \multirow{2}{*}{13384} \\
\cline { 2 - 3 } & Liquidus & 1272 & \\
\hline \multirow{2}{*}{$\mathrm{Fe}_{80} \mathrm{Si}_{10} \mathrm{~B}_{10}$} & Eutectic & 1148 & 1236 \\
\cline { 2 - 3 } & Liquidus & 123 & \\
\hline
\end{tabular}

Tab 4 Experimental DSC data of the Fe-Si-B (heating rate $10 \mathrm{~K} / \mathrm{min}$.). 


\section{References}

[1] T. Tokunaga, H. Ohtani, M. Hasebe. Thermodynamic evaluation of the phase equilibria and glassforming ability of the Fe-Si-B system. Calphad 2004;28;354-62.

[2] M. Palumbo, G. Cacciamani, E. Bosco, M. Baricco. Thermodynamic Analysis of Glass Formation in FeB System. Calphad 2001; 25; 625-37.

[3] F.E. Luborsky, J.J. Becker, J.L. Walter, H.H. Liebermann. Formation and Magnetic Properties of Fe-BSi Amorphous Alloys. IEEE Trans.Magn. 1979; 3; 1146-49.

[4] @ Metglas2605 SA1 Iron Based Alloy.

[5] Y. Suwa, S. Agatsuma, S. Hashi, K. Ishiyama. Study of Strain Sensor Using FeSiB Magnetostrictive Thin Film. IEEE Trans. Magn. 2010; 46 2; 666-69.

[6] H. Chiriac, C.S. Marinescu. New position sensor based on ultraacoustic standing waves in FeSiB amorphous wires. Sens. Actuator 2000;81;174-5.

[7] S. Li, S. Horikawa, M. Park, Y. Chai, V.J. Vodyanoy and B.A. Chin. Amorphous metallic glass biosensors. Intermetallics 2012;30;80-5.

[8] A. Makino, X. Li, K. Yubuta, C. Chang, T. Kubota, A. Inoue. The effect of $\mathrm{Cu}$ on the plasticity of $\mathrm{Fe}-$ Si-B-P-based bulk metallic glass. Scripta Mater. 2009; 60 5; 277-80.

[9] S. J. Poon, G. J. Shiftlet, F. Q. Guo, V. Ponnambalam. Glass formability of ferrous- and aluminumbased structural metallic alloys. J. Non-Cryst. Solids. 2003;317;1-9.

[10] I. Mat'ko, E. Illekova, P. Svec, P. Duhaj. Local ordering model in Fe-Si-B amorphous alloys. Mater. Sci. Eng. A 1997; 226-228; 280-84.

[11] M. A. Gibson, G. W. Delamore. Crystallization of stable and metastable eutectics in FeSiB metallic glasses. J. Mater. Sc. 1990;25;93-7.

[12] B. Aronsson, I. Engström. X-ray Investigations on Me-Si-B Systems ( $\mathrm{Me}=\mathrm{Mn}, \mathrm{Fe}, \mathrm{Co})$. Acta Chem. Scand. 1960; 14; 1403-13.

[13] Yu.V. Efimov, G.G. Mukhin, E.M. Lazarev, N.A. Korotkov, L.A. Ryabtsev, V.N. Dmitriev, T.M. Frolova. The Structure of the rapidly hardened Fe-Si-B alloys. Russ. Metall. 1986;4;167-73.

[14] N.F. Chaban, Yu.B. Kuz'ma. Phase Equilibria in the systems Manganese-Silicon-Boron and IronSilicon-Boron. Inorg. Mater. 1970; 6; 883-4.

[15] G. Shao. Prediction of amorhpous phase stability in metallic glasses. J. Appl. Phys. 2000; 88;4443-5.

[16] M. Hillert, M. Jarl. A model for alloying effects in ferromagnetic metal. Calphad 1978;2 3;227-38.

[17] A.T. Dinsdale. SGTE Data for pure elemts. Calphad 15, (1991) 317-425.

[18] T. Abe, M. Shimono, M. Ode, H. Onodera. Thermodynamic modeling of the undercooled liquid in the $\mathrm{Cu}-\mathrm{Zr}$ system. Acta Mater. 2006;54; 909-15.

[19] J. Agren, B. Cheynet, M.T. Clavaguera-Mora, K. Hack, J. Hertz, F. Sommer, U. Kattner. Thermodynamics of Supercooled Liquids and their Glass Transition. Calphad $1995 ; 19 ; 449-80$.

[20] M. Palumbo, L. Battezzati. Thermodynamics and kinetics of metallic amorphous phases in the framework of the CALPHAD approach. Calphad 2008;32; 295-314.

[21] G. Shao. Thermodynamic and kinetic aspects of intermetallic amorphous alloys. Intermetallics 2003;11;313-24.

[22] G. Shao, B. Lu, Y.Q. Liu, P. Tsakiropoulos. Glass forming ability of multi-component metallic systems. Intermetallics 2005;13;409-14.

[23] M. Palumbo, M. Satta, G. Cacciamani, M. Baricco. Thermodynamic Analysis of the Undercooled Liquid and Glass Transition in the Cu-Mg-Y System. Mater. Trans. 2006; 47;2950-55.

[24] G. Inden. Determination of Chemical and Magnetic Interchange Energies in BCC Alloys. Z. Metallkde 1975;66;577-82.

[25] N. Saunders, A.P. Miodownik. CALPHAD, A comprensive Guide. Pergamon Material Series; 1998. Chapter 8.

[26] G. Dalla Fontana, L. Battezzati. Thermodynamic and dynamic fragility in metallic glass-formers. Acta Mater. 2013;61;2260-67. 
[27] J. Lacaze, B. Sundman. An Assessment of the Fe-C-Si System. Metall. Trans. A 1991; 22 10; $2211-23$.

[28] T. Tokunaga, K. Nishio, H. Ohtani, M. Hasebe. Phase Equilibria in the Ni-Si-B System. Mater. Trans. 2003;44;1651-4.

[29] B. Hallemans, P. Wollants, and J.R. Roos. Thermodynamic reassessment and calculation of the Fe-B phase diagram. Z. Metalkde 1994; 85 10; 676-82.

[30] T. Van Rompaey, K.C. Hari Kumar, P. Wollants. Thermodynamic optimization of the B-Fe system. J. Alloy Compd. 2002;334;173-81.

[31] L.-M. Pan, in: B. Sundman (Ed.), Division of Computational Thermodynamics, SGTE Solution Database, ver. 2, Royal Institute of Technology, Stockholm, Sweden, 1994.

[32] Yu. 0. Esin, V. M. Baev, M. S. Petrushevskii, P. V. Gel'd, Izv. Adak. Nauk. SSSR Met. $1975 ; 82$.

[33] T. Miki, K. Tsujita, S. Ban-Ya, M. Hino. Activity of the constituents in molten Fe-B and Fe-B-C alloys. Calphad 2006; 30; 449-454.

[34] M.A. Van Ende, I.H. Jung. Critical thermodynamic evaluation and optimization of the $\mathrm{Fe}-\mathrm{B}, \mathrm{Fe}-\mathrm{Nd}$, B-Nd and Nd-Fe-B systems. J. Alloy Compd. 2013;548; 133-54.

[35] L. Kaufman, J.H. Perepezko, K. Hildal, D. Day, N. Yang, D. Branagan. Transformation, stability and Pourbaix diagrams of high performance corrosion resistant (HPCRM) alloys. Calphad 2009;33; 89-99.

[36] E. Kneller, Y. Khan. The Phase $\mathrm{Fe}_{2}$ B. Z. Metallkde 1987; 78;825-35.

[37] L. Battezzati, C. Antonione, M. Baricco. Undercooling of Ni-B and Fe-B alloys and their metastable phase diagrams. J. Alloy Compd.1997; 247;164-71.

[38] L- G. Voroshin, L. S. .Lyakhovich, G. G. Panich, G. F. Protasevich. The Structure of Fe-B Alloy. Sci. Heat Treat. (USSR) 1970;9;732-35.

[39] K. I. Portnoi, M. Kh. Levinshkaya, V. M. Romashov. Constitution diagram of the system iron-boron. Sov. Powder Metall. Met. Ceram. 1969;8 8;657-59.

[40] A.I. Zaitsev, N.E. Zaitseva, A.A. Kodentsov. A Thermodynamic Study of Liquid Fe-Si-B Alloys; an Influence of Ternary Associates on a Liquid : Glass Transition. Metall. Mater. Trans. B 2009;34B;887-98.

[41] E. Illekovà, P. Svec, P. Duhaj. Crystallization characterisics in the Fe-Si-B glassy ribbon system. Mater. Sci. Eng. A 1997;225; 145-52.

[42] H.H. Liebermann, J. Marti, R.J. Martis, C.P. Womg. The Effect of Microstructure on Properties and Behaviours of Annealled $\mathrm{Fe}_{78} \mathrm{~B}_{13} \mathrm{Si}_{9}$ Amorphous Alloy Ribbon. Metal. Trans. A 1989;20A; 63-70.

[43] C. Antonione, L. Battezzati, G. Cocco, F. Marino. Thermochemical and Structural Investigation of Crystallization in Fe-B and Fe-Si-B Metallic Glasses. Z. Metallkde1984;75; 714-18.

[44] A. Inoue, H. Yamamoto, T. Masumoto. Glass Transition Behavior of Fe-Al-B-Si Amorphous Alloys. Mater. Trans. 1990; 31 12;1021-27.

[45] M. Hagiwara, A. Inoue, T. Masumoto. Mechanical Properties of Fe-Si-B Amorphous Wires Produced by In-Rotating-Water Spinning Method. Metall. Trans. A 1982; 13A; 373-82.

[46] S. Gorelkin, A. S. Dubrovin, 0. D. Kolesnikov. Determination of the Heats of Formation of Intermetallics in an Isothermal Calorimeter by the Sintering Method. Russ. J. Phys. Chem. 1972; 46, 754-55.

[47] S. Sato, O. J. Kleppa. Entalpies of Formation of Borides of Iron,Cobalt and Nickel by Solution Calorimetry in Liquid Copper. Metall. Trans. B 1982; 13B;251-7.

[48] A. F. Plotnikova, N. G. Ilyushchenko, A. I. Anfinogenov, C. I. Belyaeva, S. D. Finkelshteyn, Tr. Inst.Electrochim. Ural Nauchn Tsentr. Akad. Nauk. SSSR 18, (1972) 112.

[49] S. Omori, J. Moriyama Thermodynamic Properties of $\mathrm{Fe}_{2} \mathrm{~B}$ and $\mathrm{FeB}$ by EMF Measuraments of Cells with Solids Oxide Electrolytes. Trans. Jpn. Inst. Met. 1980;21;790-96.

[50] F. A. Sidorenko, N. N. Serebremrikov, V. D. Budozhanov, Yu. V. Putintsev, S. N. Trushevskii, V. D.Korabanova, P. V. Gel'd. Thermophysical Properties of iron and cobalt monoborides. High Temp. $1977 ; 15 ; 36-9$.

[51] V.T. Witusievicz, A.A. Shcheretskii, A.K. Biletskii, V.S. Schumikhin, Rasplavy 1989;4; $102-103$. 
